\title{
FGFR1 Oncogene Partner 2
}

National Cancer Institute

\section{Source}

National Cancer Institute. FGFR1 Oncogene Partner 2. NCI Thesaurus. Code C98077.

FGFR1 oncogene partner 2 (253 aa, 29 kDa) is encoded by the human FGFR1OP2 gene.

This protein may be involved in wound responses. 